processes of life seem to be large enough forpossibly and even probably-safeguarding the essential course of these processes against any perceptible direct and immediate manifestation of the Heisenberg uncertainty.

The preceding remarks have been elicited by the first page of a highly interesting sketch by Prof. F. G. Donnan, "Integral Analysis and the Phenomena of Life" (Acta Biotheoretica, Series A, vol. 2, Pars 1, 1936 ; Leyden : E. J. Brill), though not by way of contradiction. Prof. Donnan is not concerned with the question of free-will. His idea is that an organism is to be regarded as a 'historical' system, whose reactions at a given moment are not determined alone by its surroundings and by its momentary state, but also by what has happened to that organism during a certain previous period. This is a highly attractive view, and the mathematical treatment proposed by Prof. Donnan a very suggestive one - even if one should hesitate to agree with the view (which he considers essential) that some of the historical traces are not engraved in the momentary state otherwise than by modifying its reactivity.

\title{
The Institute of Experimental Psychology at Oxford
}

$\mathrm{T}$ HE University of Oxford has recently enacted a statute establishing an Institute of Experimental Psychology, at which active work will be begun in the autumn. Dr. William Brown, Wilde reader in mental philosophy in the University, has been appointed its first director, with Dr. William Stephenson as his assistant. The management of the Institute is in the hands of a committee consisting of the Vice-Chancellor, a representative appointed by each of the boards of the Faculties of Medicine, Literæ Humaniores, Biological Sciences and Social Studies, together with the director.

Thus Oxford has at length officially fallen into step with the movement that has been going on for more than fifty years, the aim of which has been to free psychology from the exclusive tutelage of philosophy, and establish it as an independent, empirical and experimental science. Such freedom, however, does not imply separation, nor can the independence be more than a relative one.

In taking its place among the other natural sciences, the data of all of which provide grist for the philosophical mill, psychology will still look to philosophy, as they do, for the solution of some of the ultimate problems; though it will pursue its own proximate quests by its own empirical line of approach and the use of its own appropriate methods. Grouped together with the other sciences, again, and particularly with the biological and social sciences, there will be much overlapping and interlacing, which can only result in great mutual advantage to them all. Both these points have most wisely been taken into consideration in the constitution of the committee of management of the new Institute.

The foundation of this laboratory at Oxford is in a sense a historic event. For centuries, the University has been the home of philosophy, of which psychology has always been an integral and essential part. In the Middle Ages, Roger Bacon and Duns Scotus, no mean psychologists, stand out amongst its scholars. In the seventeenth century, the 'father' of modern psychology, John Locke, author of the famous "Essay Concerning Human Understanding", was a student of Christ Church. When the Wilde readership was founded in 1898 , a distinguished psychologist, G. F. Stout, was appointed to hold it; and he was succeeded by a no less distinguished teacher of the science than William McDougall.

An age-long tradition was there ; the conversion of rational into empirical psychology had already begun. But as yet there was no established laboratory in which systematic research could be prosecuted. One is tempted to ask why Oxford should have lagged behind when Cambridge, London, Manchester, Edinburgh forged ahead, in company with most other European and American universities, following the lead of Wundt at Leipzig. Was it opposition from the ancient vested interests of philosophy? Was it the belief that scientific psychology was a mere appendage of physiology? Did the terms of the Wilde readership, excluding experimental psychology explicitly from its purview, stand in the way? Of recent years, at any rate, it was none of these things. Before the Great War, McDougall was able for a time to direct a laboratory, housed in rooms belonging to the Department of Physiology, and having access to apparatus in use there. Solid work had already begun; and, but for the upheaval of the War years and their aftermath, it might have become permanent. But the accommodation was then urgently needed for other purposes, and funds were unavailable; so the project had to be abandoned. 
During Brown's fifteen years' tenure of the Wilde readership, several attempts were again made in this direction; but, though encouraged by much friendly sympathy on the part of the authorities, the same lack of funds and rooms in which to house a laboratory made it impracticable. Last year, however, a generous offer of $£ 10,000$ was made through the Wilde reader for this purpose; and it was gladly accepted by the University. The curators of the University Chest will provide the necessary accommodation; and a further sum of $£ 500$, together with a grant of $£ 150$ a year for five years from the Rockefeller benefaction for research in the social sciences, is to go to the Institute.

\section{Centenary of Darwin's Visit to the Galapagos Islands}

\section{Issue of Commemorative Stamps by Ecuador}

$\mathrm{D}^{\mathrm{IS}}$ ISTINGUISHED men of science have, before now, been commemorated on postage stamps by countries sufficiently civilized to value their achievements, but it does not appear that any particular event in the history of science has hitherto been celebrated in this way. It has been left to the Republic of Ecuador to mark, by the issue of a special series of stamps, the centenary of a critical point in the development of the evolution theory. It was on September 16, 1835, that Darwin first landed on Chatham Island in the Galapagos group, where, as he wrote in his "Journal of Researches", "we seem to be brought somewhat near to that great fact-that mystery of mysteries-the first appearance of new beings on this earth". The influence of what he saw there on the later development of his thought is now a commonplace of biological teaching, although some modern writers on evolution might be well advised to read again his own account of his observations and the conclusions to which he was led.

The six stamps which are here reproduced bear designs associated with the islands or with Darwin's visit, the introduction of a portrait of Christopher
Columbus being apparently suggested by the Ecuadorean name for the group, "Archipelago of Colon". The portrait of Darwin is taken from a well-known photograph now hanging in Down

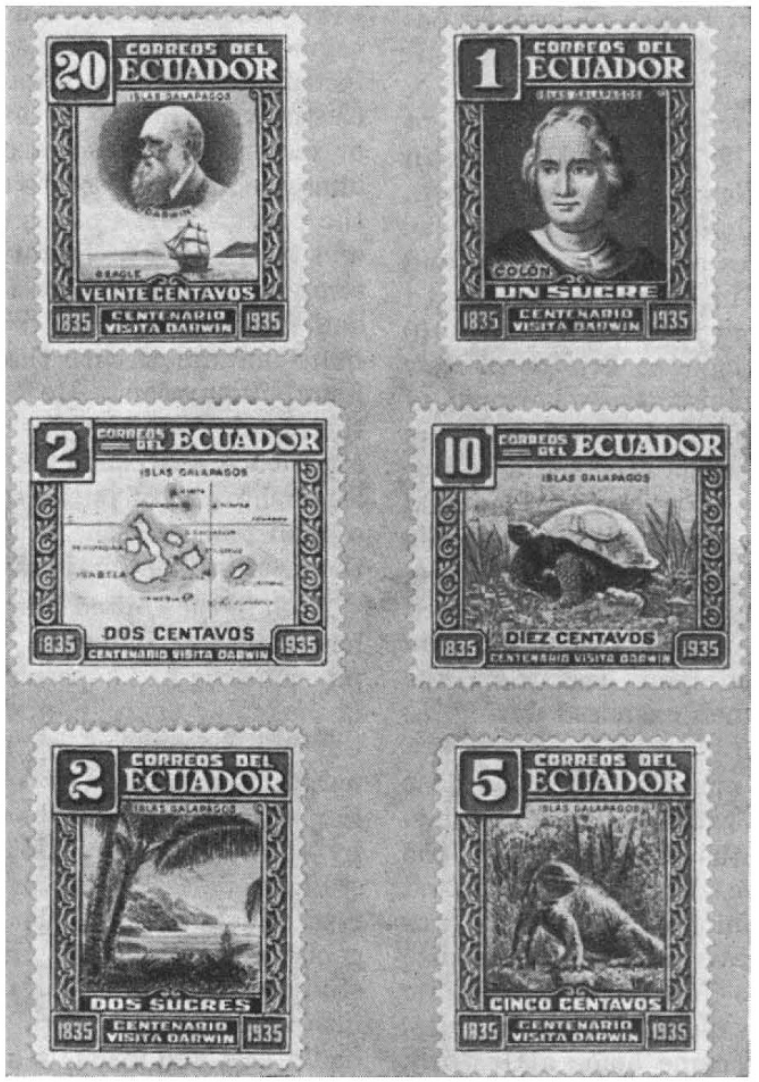
memoration of the centenary of Darwin's visit to the Galapagos Islands in the Beagle in 1835 .
Fra. 1. Stamps issued by the Ecuadorean Government in com-

House ; it represents him in his old age, and is probably that by which he is best remembered, although at the time of his visit to the Galapagos Islands he was, of course, a young man of twentysix years. A view, presumably representing some place in the islands, has a group of coconut palms in the foreground. If this is correct, it indicates a change in the flora since Darwin's time, for he notes in his "Journal", "I saw nowhere any member of the palm family". Two of the designs represent reptiles characteristic of the islands, one of the land iguanas and one of the giant tortoises from which the group takes its name. How many zoologists, one wonders, associate "Galapagos" with the familiar but etymologically obscure word "carapace"?

It is important to remember that one of the things that struck Darwin on visiting the islands was the abundance of individuals, especially of some of the larger reptiles. This density of 